\title{
Condrossarcoma mixóide em um coelho
}

\author{
Myxoid chondrosarcoma in a rabbit \\ Tuane Nerissa Alves Garcez' ${ }^{1}$, Fábio dos Santos Teixeira', Marianne Lamberts' , \\ Marcelo de Souza Muccillo', Wanessa Krüger Beheregaray², Anamaria de Oliveira Fernandes ${ }^{3}$, \\ Giordano Cabral Gianotti ${ }^{2}$ \& Emerson Antonio Contesini ${ }^{4}$
}

\begin{abstract}
RESUMO
Tumores ósseos primários em animais, com exceção dos osteossarcomas, são raros. O condrossarcoma é uma neoplasia maligna, de crescimento lento, proveniente de tecido cartilaginoso. É um tumor localmente invasivo, tendo grande propensão a recidivas, mas baixa incidência de formação de metástases. O diagnóstico definitivo é dado pelo exame histopatológico. A remoção cirúrgica, com obediência aos preceitos da cirurgia oncológica é o tratamento indicado. Foi atendido, no Hospital de Clínicas Veterinárias da Universidade Federal do Rio Grande do Sul, um coelho, sem raça definida (SRD), macho, não castrado, com aproximadamente três anos de idade e 4,3kg de peso, apresentando claudicação e aumento de volume na região distal do membro pélvico direito. $\mathrm{O}$ exame histopatológico revelou diagnóstico de condrossarcoma mixóide de grau II. Realizou-se a amputação do membro afetado. O paciente demonstrou uma boa recuperação dos movimentos nos primeiros dias após a cirurgia, retornando às funções que realizava anteriormente, como caminhar, correr e saltar.
\end{abstract}

Descritores: oncologia, tumor ósseo, condrossarcoma mixóide, amputação.

\begin{abstract}
Primary bone tumors are rare in animals, with the exception of osteosarcomas. Chondrosarcoma is a malignant, slow-growing cartilage-forming tumor. It is a potentially recurring and locally invasive neoplasm, though metastasis rates are low. Definitive diagnosis comprises histopathological examination. Surgical excision, observing the principles of oncologic surgery, is indicated as the treatment of choice. An approximately 3-year-old, 4.3-kg mixed-breed non-castrated male rabbit was referred to the Hospital de Clínicas Veterinárias, Universidade Federal do Rio Grande do Sul (UFRGS), presenting claudication and an enlarged growth in the right distal pelvic limb. The growth was diagnosed as myxoid chondrosarcoma grade II by histopathological examination. The affected limb was amputated. The patient showed a good recovery of movements over the first days following surgery, and was able to resume previous activities such as walking, running and leaping.
\end{abstract}

Keywords: oncology, bone tumor, myxoid chondrosarcoma, amputation. 


\section{INTRODUÇÃO}

Tumores ósseos primários em animais, com exceção dos osteossarcomas, são raros [1], e incluem condrossarcomas, fibrossarcomas, hemangiossarcomas, tumores de células gigantes, lipossarcomas e sarcomas de células sinoviais [2].

O condrossarcoma é uma neoplasia maligna de crescimento lento [1], proveniente de tecido cartilaginoso [3], sendo, em cães e gatos, mais comumente encontrada no esqueleto axial [2]. É um tumor localmente invasivo, tendo grande propensão a recidivas [3], mas baixa incidência de formação de metástases [4]. O diagnóstico é dado pelo exame histopatológico.

$\mathrm{O}$ condrossarcoma possui similaridades histológicas com diversos outros tumores. Dentre eles, os fibromas condromixóides [5,6], osteossarcomas, fibrossarcomas [7] e condromas [8]. Esta neoplasia pode ser classificada em dois subtipos: o mixóide e o mesenquimal. [9]. Podendo, ainda, ser divididos em três graduações histológicas (graus I, II, III), de acordo com o grau de diferenciação celular [3,10,11]. As duas variantes histológicas têm na indicação cirúrgica com margens oncológicas o principal tratamento, não havendo consenso na literatura sobre a complementação terapêutica com radioterapia ou quimioterapia $[8,12]$. O objetivo deste trabalho é relatar um caso de condrossarcoma mixóide em um coelho, abordando os sinais clínicos, o tratamento realizado, as complicações e os resultados obtidos.

\section{RELATO DE CASO}

Foi atendido, no Hospital de Clínicas Veterinárias (HCV) da Universidade Federal do Rio Grande do Sul (UFRGS), um coelho, sem raça definida (SRD), macho, não castrado, com aproximadamente três anos de idade e pesando 4,3kg. Ao exame físico, o paciente apresentava claudicação e aumento de volume na região distal do membro pélvico direito (MPD). O nódulo apresentava-se firme e aderido à palpação e possuía sinais de intensa neovascularização periférica (Figuras 1 e 2). O proprietário relatava que o nódulo vinha crescendo progressivamente há aproximadamente um ano. $\mathrm{O}$ animal mostrava sinais de dor local quando manipulado. Não havia outras alterações ao exame físico.

Foi realizado exame radiográfico (RX) do membro afetado e biópsia aspirativa por agulha fina (BAAF). O exame radiográfico (Figuras 3A e 3B) revelou imagem compatível com destruição articular severa. A citologia realizada através do material coletado por BAAF foi inconclusiva. No entanto, baseado no exame físico e radiológico, recomendou-se a amputação do membro afetado.

Optou-se por amputação do membro no nível proximal do fêmur (Figura 4) e o material foi enviado para a análise histopatológica. O laudo histopatológico revelou diagnóstico de condrossarcoma mixóide de grau II. O proprietário não retornou ao hospital para retirada dos pontos e revisão clínica em dez dias, conforme indicação do veterinário responsável. No entanto, mediante contato telefônico, após quinze dias de pós-operatório, o mesmo relatou que o paciente apresentou boa recuperação dos movimentos, retornando às funções que realizava anteriormente, como caminhar, correr e saltar.

\section{DISCUSSÃO}

O condrossarcoma é uma neoplasia maligna de crescimento lento [1], o que, neste caso, fica confirmado pelo relato do proprietário, que afirmava ter notado o crescimento progressivo do nódulo há aproximadamente um ano. Em humanos, este tipo tumoral pode desenvolver-se primariamente tanto no sistema esquelético quanto em sítios extraesqueléticos [13,14], apresentando localização pouco frequente na região da cabeça e do pescoço, sendo mais comum em pelve, fêmur, costelas, úmero, escápula, fíbula, sacro e esterno [11]. Em cães e gatos, é mais comumente encontrado no esqueleto axial [2]. Diferentemente da expectativa para animais, a localização do tumor era no esqueleto apendicular, semelhante à localização esperada em humanos.

Esta neoplasia pode ser classificada em dois subtipos: subtipo mixóide, diagnosticado com mais frequência em condrossarcomas esqueléticos, e subtipo mesenquimal, mais comumente diagnosticado em sítios extraesqueléticos [9]. O diagnóstico é dado pelo exame histopatológico. É característico do condrossarcoma o encontro de células cartilaginosas gigantes com pleomorfismo nuclear e hipercromatismo compostos por múltiplos nódulos que se interconectam com tamanhos variados [15]. O espaço intercelular pode ser de origem condróide ou mixomatosa [16]. Ainda, podem ser divididos em três graduações histológicas (graus I, II, III), de acordo com o grau de diferenciação celular [3,10,11]. Esses graus de diferenciação celular são classificados de acordo com taxa de mitose, celularidade e tamanho nuclear. O diagnóstico de condrossarcoma grau II é obtido pela presença de núcleos com proporções maiores, 


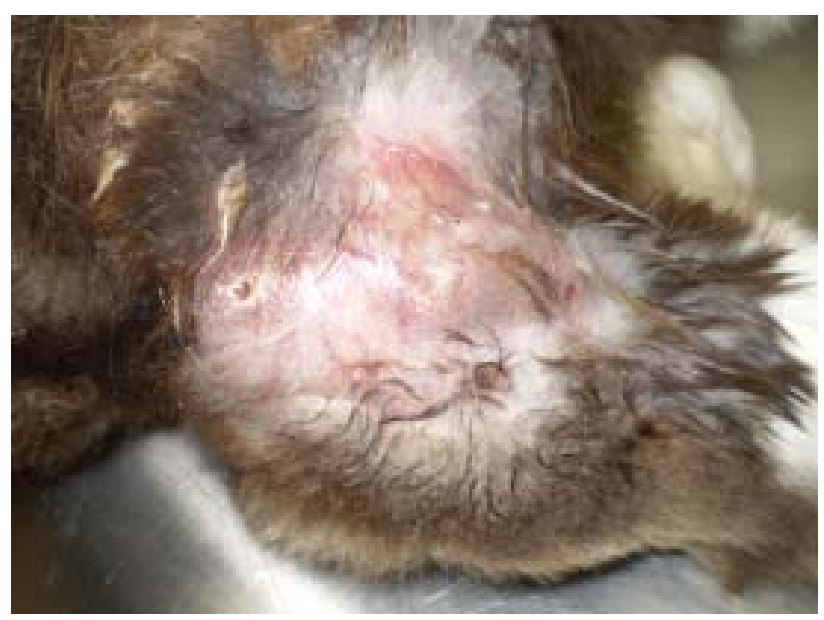

Figura 1. Coelho, macho, SRD, três anos de idade. Aspecto da lesão ao exame clínico. Notar aumento de volume na porção distal do membro.

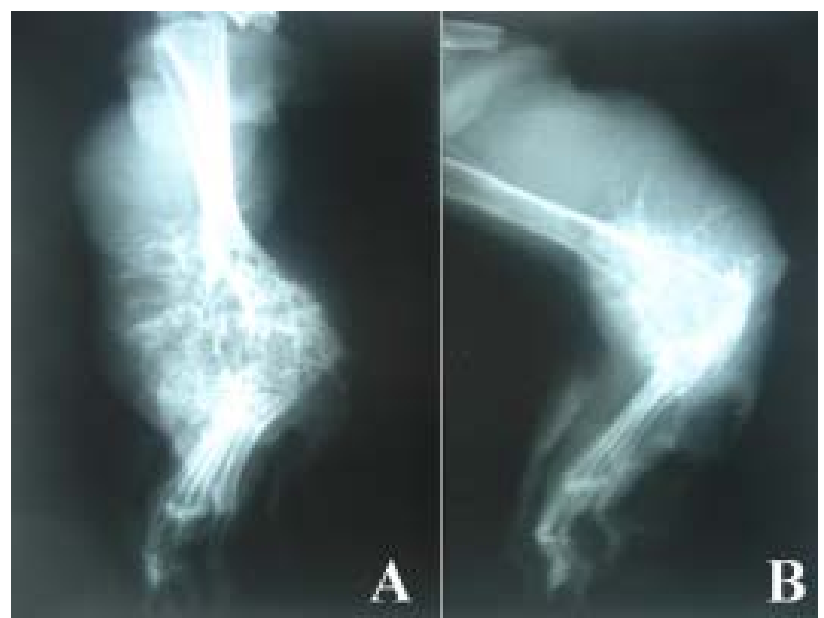

Figura 3. [A] Exame radiográfico, vista dorso-ventral de membro posterior direito, mostrando severa destruição articular. [B] Exame radiográfico, vista látero-lateral de membro posterior direito, mostrando severa destruição articular.

com pequena taxa de mitose e espaço intercelular comumente mixóide. Após análise histopatológica, classificou-se o material obtido como um condrossarcoma mixóide de grau II, por apresentar a presença de material mixóide no espaço intercelular.

Geralmente os condrossarcomas causam destruição local e invasão de tecidos adjacentes. O comportamento de baixo grau de agressividade do condrossarcoma mixóide é atualmente questionado por alguns autores, sendo melhor descrito como tumor de grau intermediário de malignidade [17]. A disseminação hematógena ocorre tardiamente [15] e o comprometimento metastático se dá principalmente para o pulmão em ambos os tipos [18]. Em humanos, não é relatada metástase no grau I; porém, os graus II e III apresentam taxas de $10 \%$ e $71 \%$, respectivamente [16]. O animal

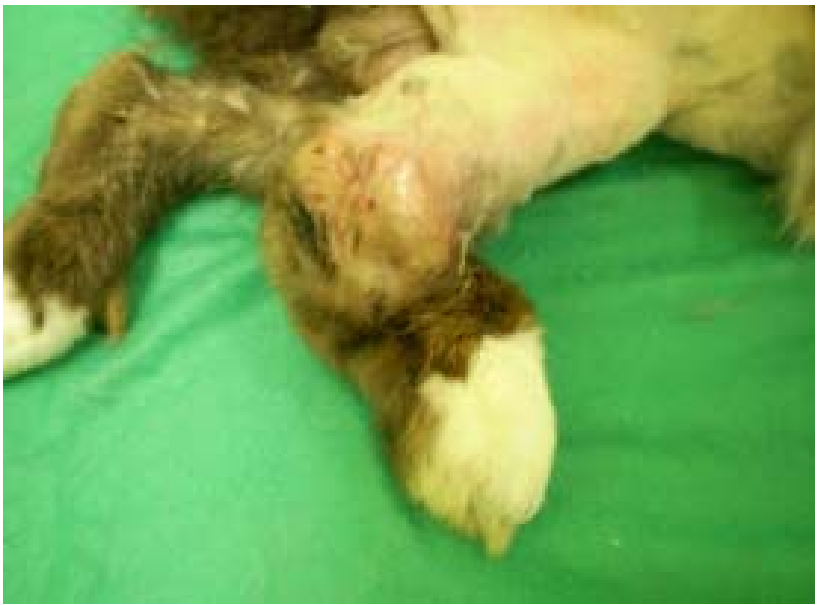

Figura 2. Coelho, macho, SRD, três anos de idade. Aumento de volume articular em região distal de membro posterior direito e neovascularização periférica.

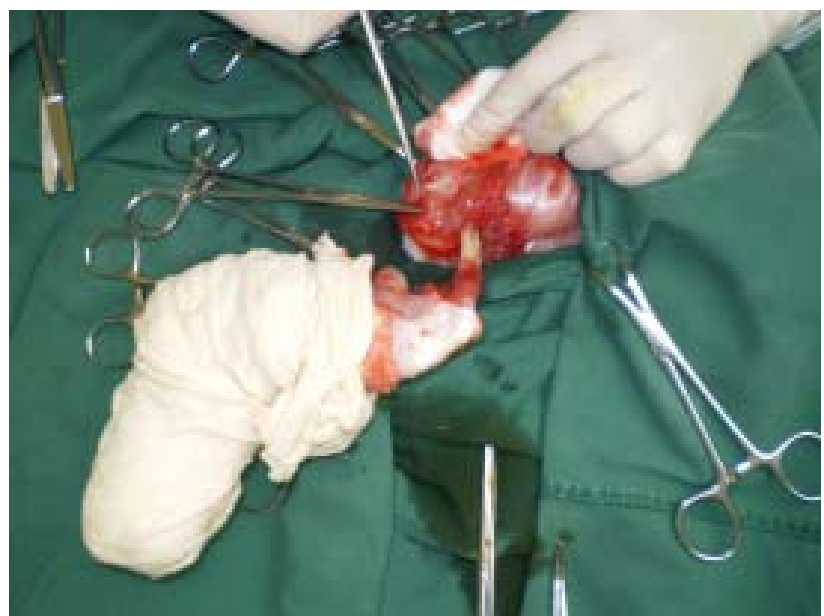

Figura 4. Amputação de membro posterior direito. Técnica cirúrgica de amputação a nível proximal do fêmur.

não apresentava linfonodos satélites reativos ao exame clínico; no entanto, não foi realizado Rx de tórax para pesquisa de metástase, apesar de tratar-se de um condrossarcoma de grau II, visto que o animal não retornou para revisão, ocasião na qual se teria o resultado do exame histopatológico.

Em humanos, as condutas quimioterápica e radioterápica são reservadas para complementação terapêutica adjuvante ou método paliativo de abordagem. Em medicina veterinária o tratamento para o condrossarcoma é a excisão cirúrgica radical [4]. Assim, optou-se pela amputação como única forma de tratamento para o caso.

O prognóstico está relacionado a três fatores: localização, grau e possibilidade de ressecção. $\mathrm{O}$ grau de diferenciação é muito importante, sendo pior o prognóstico nos tumores de maior grau [3,7]. Considerou-se um 
prognóstico favorável, já que se tratava de um tumor de graduação intermediária e, por ter sido realizada excisão cirúrgica com ampla margem de segurança.

Quanto ao procedimento cirúrgico, a área de lesão de tecidos moles ou ósseos determina qual das várias técnicas de remoção de membro pélvico disponíveis é a mais indicada. Em cães machos, a amputação a nível proximal do fêmur é utilizada pela sua praticidade e por possibilitar o recobrimento do escroto e prepúcio e proteção da genitália externa [20]. Neste caso, optouse por esta técnica, por tratar-se de um procedimento mais rápido e prático, além de trazer ao paciente os benefícios protetores, como citado anteriormente.

O paciente demonstrou uma boa recuperação dos movimentos nos primeiros dias após a cirurgia, retornando às funções que realizava anteriormente, como caminhar, correr e saltar. Assim, a amputação, além de apresentar bons resultados estéticos e funcionais, controla o tumor primário e fornece alívio da dor com pouca ou nenhuma redução na mobilidade e qualidade de vida, o que faz com que o procedimento seja, em geral, bem aceito pelo proprietário [21].

\section{REFERÊNCIAS}

1 Morris J. \& Dobson J. 2001. Skeletal system. In: Morris J. \& Dobson J. (Eds). Small Animal Oncology. Oxford: Blackwell Science, pp.78-93.

2 Ogilvie G.K. 2004. Tumores ósseos. In: Rosenthal R.C. (Ed). Segredos em Oncologia Veterinária. Porto Alegre: Artmed, pp.183-191.

3 Burkey B.B., Hoffman H.T., Baker S.R., Thorton A.F. \& McClatchey K.D. 1990. Chondrosarcoma of the head and neck. Laryngoscope. 100: 1301-1305.

4 Shaw D. \& Ihle S. 1999. Doenças Oncológicas. In: Medicina Interna de Pequenos Animais. Porto Alegre: ARTMED, pp.630643.

5 Koay C.B., Freeland A.P. \& Athanasou N.A. 1995. Chondromixoid fibroma of the nasal bone with extension into the frontal and ethmoidal sinuses. Journal of Laryngology \& Otology. 109: 258-261.

6 Baujat B., Attal P., Racy E., Quillard J., Parker F., Evennou A. \& Bobin S. 2001. Chondromyxoid fibroma of the nasal bone with extension into the frontal and ethmoidal sinuses: report of one case and a review of the literature. American Journal of Otolaryngology. 22: 150-153.

7 Koka V., Vericel R., Latigau E., Lusinchi A. \& Schwaab G. 1994. Sarcomas of nasal cavity and paranasal sinuses: chondrosarcoma, osteosarcoma and fibrosarcoma. Journal of Laryngology \& Otology. 108: 947-953.

8 Nakashima Y., Unni K.K., Shives T.C., Swee R.G. \& Dahlin D.C. 1984. Mesenchymal chondrosarcoma of bone and soft tissue: a review of 111 cases. Cancer. 57: 2444-2453.

9 Casadei R., Ricci M., Ruggieri P., Biagini R., Benassi S., Picci P. \& Campanacci M. 1991. Chondrosarcoma of the soft tissues: two different subgroups. Journal of Bone Joint Surgery. 73: 162-168.

10 Beneck D., Seldman I. \& Jacobs J. 1984. Chondrosarcoma of the nasal septum: a case report. Head and Neck Surgery. 7: 162-167.

11 Finn D.G., Goepfert H. \& Batsakis J.G. 1984. Chondrosarcoma of the head and neck. Laryngoscope. 94: 1539-1544.

12 Patel S.Y.R., Burgess M.A., Papadopoulos N.E., Linke K.A. \& Benjamin R.S. 1995. Extraskeletal myxoid chondrosarcoma. Long-term experience with chemotherapy. American Journal of Clinical Oncology. 18: 161-163.

13 Miller J.M., Walshaw R. \& Bourque A.C. 2005. Primary splenic mesenchymal chondrosarcoma in a dog. Canadian Veterinary Journal. 46: 163-165.

14 Romanucci M., Bongiovanni L., Petrizzi L. \& Della Salda L. 2005. Cutaneous extraskeletal mesenchymal chondrosarcoma in a cat. Veterinary Dermatology. 16: 121-124.

15 Lacovara J., Patherson K. \& Reaman G.H. 1992. Primary nasal chondrosarcoma. American Journal of Pediatric Hematology/Oncology. 14: 158-162.

16 Evans H.L., Ayala A.G. \& Romsdahl M.M. 1977. Prognostic factors in chondrosarcoma of bone: a clinicopathologic analysis with emphasis on histologic grading. Cancer. 40: 818-831.

17 McGrory J.E., Rock M.G., Nascimento A.G. \& Oliveira A.M. 2001. Extraskeletal myxoid Chondrosarcoma. Clinical Orthopaedics and Related Research. 382: 185-190.

18 Campos G.G., El Hadj L.A., Araújo M.L., Mello P.P \& Mello L.F.P. 2004. Condrossarcoma laríngeo: relato de caso e revisão de literatura. Revista Brasileira de Otorrinolaringologia. 70: 823-826. 
Garcez T.N.A., Teixeira F.S., Lamberts M., Muccillo M.S., Beheregaray W.K., Fernandes A.O., Gianotti G.C. \& Contesini E.A. 2009. Condrossarcoma mixóide em um coelho.

19 Cubas Z., Silva J. \& Catão-Dias J.L. 2007. Tratado de Animais Selvagens. São Paulo: Roca. 1376p.

20 Knapp D.W. \& Constantinescu G.M. 1996. Amputação e desarticulação da perna traseira. In: Bojrab M.J. (Ed). Técnicas Atuais em Cirurgia de Pequenos Animais. 3.ed. São Paulo: Roca, pp.684-691.

21 Vail D.M. \& Withrow S.J. 2001. Tumors of the skeletal system. In: Withrow S.J. \& MacEwen E.G. (Eds). Small Animal Clinical Oncology. 4th edn. Philadelphia: W. B. Saunders, pp.540-582. 